\title{
Letter from the Board of Directors
}

\section{New policy concerning expanded European and non-European A\&A memberships}

It is now thirty-five years since the scientific journal Astronomy \& Astrophysics $(A \& A)$ was founded by the merging of six national journals from four European nations, namely France, Germany, the Netherlands and Sweden; Belgium and the other Nordic countries, Denmark, Finland and Norway, also participated. They were subsequently joined by five other western European nations, namely Austria, Greece, Italy, Spain and Switzerland (Norway later withdrew). A\&A has no international legal status as such but is represented by the European Southern Observatory (ESO), which also manages its financial transactions.

In the early nineteen-nineties, $A \& A$ with great foresight took an important step - which the European Union would follow more than a decade later - by incorporating eastern European countries into its sponsoring membership: the Czech Republic, Hungary, Poland and the Slovak Republic; Estonia became a full member in 1998. A\&A was now truly "A European Journal", as then stated on the front cover.

In the meantime, $A \& A$ grew in importance as a vehicle for world-wide dissemination of astronomical research and an ever-increasing number of high-quality papers began streaming into the $A \& A$ Editorial offices from non-European countries, as well as from other European non-member countries. It became obvious to us that $A \& A$ no longer was merely a European Journal and in 2001 we removed the "A European Journal" from the front cover.

Eventually, some of these non-European countries began approaching us with queries about potential membership in $A \& A$ and in 2002 we admitted the first such country, Argentina, with an observer status. Meanwhile, the Board intensified its study of the financial and administrative consequences of a wider expansion including the admission of member countries beyond Europe - a special subcommittee was appointed.

The Board of Directors, at its meeting in Tartu, Estonia on 8 May 2004, made the important decision - after a lengthy and thorough discussion - that A\&A will henceforth consider applications for sponsoring membership from any country in the world with well-documented active and excellent astronomical research. Each application will be carefully treated on a case-by-case basis. Subsequently, at this meeting, the Board admitted Argentina to full membership in $A \& A$ starting on 1 January 2005. In addition, three other applicants were admitted to observer status, namely Brazil, Chile and Portugal. The above-mentioned special Board subcommittee will continue its work and submit recommendations on the restructuring of the Board and its Executive Committee, a necessary consequence of the foreseen expansion. 